\title{
Three-year follow-up of visual outcome and quality of life in patients with age-related macular degeneration
}

This article was published in the following Dove Press journal:

Clinical Ophthalmology

25 February 2013

Number of times this article has been viewed

\author{
Lena Rung' \\ Monica Lövestam-Adrian² \\ 'Department of Ophthalmology, \\ Helsingborg Hospital, Helsingborg, \\ ${ }^{2}$ Department of Ophthalmology, Lund \\ University, Skåne University Hospital, \\ Malmö, Sweden
}

Background: The purpose of this study was to evaluate the visual outcome and self-reported vision-targeted health status in patients treated with intravitreal ranibizumab for wet age-related macular degeneration (AMD).

Methods: A total of 51 eyes from 50 patients aged $76 \pm 7$ years, with wet AMD not previously treated, were included in this prospective study. Best corrected visual acuity was examined using Early Treatment Diabetic Research Study charts and near vision reading. All patients underwent an ophthalmological examination, including fluorescein and indocyanine green angiography (occult cases) and optical coherence tomography. The Visual Function Questionnaire test was completed before and $37 \pm 7$ months after the start of intravitreal injections.

Results: The patients received a mean number of 7.8 \pm 5.0 (range 2-22) injections. One month after the third intravitreal injection, significant improvement was seen in both visual acuity (53 \pm 14 to $61 \pm 14$ letter, $P=0.001$ ) and near vision ( $17 \pm 9$ to $11 \pm 8$ points, $P=0.001$ ). During follow-up, mean visual acuity decreased from $53 \pm 14$ to $44 \pm 24$ letters $(P=0.011)$, and near vision decreased from $17 \pm 9$ to $20 \pm 11$ points $(P=0.048)$. Despite visual impairment, the quality of life test revealed no significant decrease in mental health $(P=0.529)$ or ability to read a newspaper $(P=0.21)$, but a decrease in distance activities (reading street signs, steps, going to the theater) from $57 \pm 27$ to $46 \pm 31$ points $(P=0.007)$ was documented.

Conclusion: Decreased visual acuity was related to a decrease in self-reported visual function for distance activities, while mental health items, such as worrying, were not influenced.

Keywords: visual outcome, quality of life, age-related macular degeneration

\section{Introduction}

Age-related macular degeneration (AMD) is one of the leading causes of vision loss in older people in the Western world. ${ }^{1,2}$ With an aging population, the figures are likely to rise. The most common variant of AMD is the untreatable dry type $(85 \%)$, while the wet variant with new choroidal neovascularizations (CNV) has attracted most attention recently because of new treatment options. Two controlled studies, MARINA (Minimally Classic/Occult Trial of the Anti-VEGF Antibody Ranibizumab In the treatment of Neovascular AMD) in occult $\mathrm{CNV}^{3}$ and the ANCHOR (Anti-VEGF Antibody for the Treatment of Predominantly Classic Choroidal Neovascularization in AMD) study in predominantly classic $\mathrm{CNV}^{4,5}$ have shown that ranibizumab (Lucentis ${ }^{\circledR}$, Novartis, Basel, Switzerland) is effective in improving visual acuity after 2 years of monthly treatment.

In view of the large number of people with wet AMD, there has been a practical need to reduce the frequency of injections, and treatment in clinical practice has been
Adrian

Department of Ophthalmology, Lund University, Skåne University Hospital, SE-20502, Malmö, Sweden Tel +4646I7 1650

Email monicaladrian@gmail.com 
based on clinical indications rather than monthly monitoring. Under these circumstances, it cannot be presumed that the same results will be achieved as in the controlled studies.

Visual outcome does not fully capture visual function, and visual functioning ${ }^{6}$ and vision-related well-being have attracted attention recently. ${ }^{7,8}$ Furthermore, near vision and the ability to read a book have been addressed in a cohort treated with ranibizumab in a recent paper by Frennesson et al. ${ }^{9}$

The National Eye Institute Visual Function Questionnaire (NEI VFQ-25) is an accepted tool for measuring the dimensions of self-reported vision-targeted health status ${ }^{6}$ and has been evaluated in patients with $\mathrm{AMD}^{7,8}$ and in patients treated with ranibizumab for AMD. ${ }^{10}$

In the present prospective follow-up study of patients treated under usual care, visual acuity and near vision were measured at baseline and after 3 and 37 months of treatment with ranibizumab, and related to changes in quality of life using the NEI VFQ-25.

\section{Materials and methods}

Sixty-six consecutive patients diagnosed with wet AMD and attending the outpatient clinic at the Department of Ophthalmology in Helsingborg were included in this prospective study. Only one eye per participant was studied, and no patient had been treated previously for AMD or any other retinal disease.

\section{Patient characteristics}

Sixty-six patients were monitored and completed the NEI VFQ-25 questionnaire at 3 months and, of these, 51 patients were monitored further and completed the questionnaire again at 37 months. Of the patients who did not attend the last visit, six had died, two had moved, and seven did not want to participate. The cause of death in the six patients who died was not related to treatment with anti-vascular endothelial growth factor.

In patients monitored for only 3 months, near vision at baseline and at 3-month follow-up, as well as time from first symptoms to treatment, did not differ from the patient group monitored for 37 months, but patients who died $(n=6)$ were older at baseline $(82 \pm 11$ years versus $76 \pm 7$ years, respectively). For the entire group, age at baseline was $76 \pm 7$ years and the mean time from first symptoms to treatment was 14 (range 2-72) weeks. The patients received, on average, $7.8 \pm 5.0$ injections during the 37-month follow-up period.

Examination included best corrected visual acuity (BCVA) using the Early Treatment Diabetic Research Study (ETDRS) chart and near vision using the Swedish Tomteboda chart (Tomteboda Resource Centre for Visually Handicapped Children, Stockholm, Sweden) which is graded in typographical points, the smallest text being 4 points and the largest 24 points. A thorough clinical examination was performed, including slit-lamp and fundus biomicroscopy, intraocular pressure measurement, fundus photography (Topcon TRC-50 IX, Tokyo, Japan), fluorescein and indocyanine green angiography, and optical coherence tomography (Zeiss Humphrey Instruments, Dublin, CA, USA).

\section{Treatment}

All patients were initially given three injections at monthly intervals with ranibizumab. A decision on reinjection was then made, based on visual acuity and the findings of optical coherence tomography.

\section{NEI VFQ-25 questionnaire}

The National Eye Institute 25-item Visual Function Questionnaire version $2000^{11}$ was used as an interview instrument to evaluate self-reported vision-targeted health status. The test includes a 25 -item base set of questions, and the results were calculated according to published guidelines for the NEI VFQ-25. All items are scored such that a high score represents better functioning. The questionnaire was completed during the examination visits, and an authorized Swedish version, the VFQ-25-Swedish/Sweden (vfq, S001_1), was used. Mean changes in NEI VFQ-25 subscale scores from baseline to the follow-up interviews at 3 and 37 months were registered and related to different visual outcomes. Scores for the 25 questions were averaged for each item to generate the prespecified VFQ-25 subscales. The averaged item scores at baseline and at the 37-month follow-up are presented in Table 1. Calculations are based on the averaged subscale scores.

\section{Statistics}

Calculations were done using the Statistical Package for Social Sciences for Windows version 18.0 (SPSS Inc, Chicago, IL, USA). Values are given as the mean \pm standard deviation or median and range. The Student's $t$-test was used for normally distributed data and the Mann-Whitney $U$ test for skewed data. Spearman's rho was used to calculate correlations between the parameters.

\section{Results}

\section{Visual acuity}

BCVA increased one month after the third intravitreal injection, from $53 \pm 14$ letters to $61 \pm 14$ letters on the 
Table I Responses to questions in the NEI VFQ-25 subscales at baseline and at 37-month follow-up $(n=51)$

\begin{tabular}{|c|c|c|c|}
\hline Questions & Baseline & 37 months & $P$ \\
\hline General health & $56 \pm 26$ & $46 \pm 24$ & 0.004 \\
\hline General vision & $55 \pm 22$ & $56 \pm 23$ & 0.512 \\
\hline Ocular pain & $83 \pm 22$ & $74 \pm 29$ & 0.028 \\
\hline $\begin{array}{l}\text { Near activities (reading } \\
\text { newspaper, seeing well at } \\
\text { a close distance, finding things } \\
\text { on a crowded shelf) }\end{array}$ & $51 \pm 23$ & $50 \pm 27$ & 0.831 \\
\hline $\begin{array}{l}\text { Distance activities (street signs, } \\
\text { shop names, steps, stairs } \\
\text { in dim light, theater) }\end{array}$ & $57 \pm 27$ & $46 \pm 31$ & 0.007 \\
\hline $\begin{array}{l}\text { Mental health (worrying, sense } \\
\text { of frustration, "control } \\
\text { over what I am doing") }\end{array}$ & $58 \pm 29$ & $61 \pm 31$ & 0.529 \\
\hline $\begin{array}{l}\text { Social functioning } \\
\text { (social life, company) }\end{array}$ & $74 \pm 27$ & $65 \pm 30$ & 0.021 \\
\hline $\begin{array}{l}\text { Role difficulties } \\
\text { (limitations in daily life) }\end{array}$ & $67 \pm 28$ & $56 \pm 32$ & 0.026 \\
\hline Dependency & $71 \pm 33$ & $65 \pm 33$ & 0.139 \\
\hline Color vision (matching clothes) & $81 \pm 30$ & $65 \pm 30$ & 0.001 \\
\hline
\end{tabular}

Note: Text within parentheses is a description of the different questions included. Abbreviation: NEI VFQ-25, National Eye Institute Visual Function Questionnaire.

ETDRS charts $(P=0.001)$, and near vision improved from $17 \pm 9$ points to $11 \pm 8$ points $(P=0.001)$. At the final follow-up at 37 months, mean BCVA had decreased from $53 \pm 14$ letters at baseline to $44 \pm 24$ letters $(P=0.011)$, and near vision had decreased from $17 \pm 9$ points to $20 \pm 11$ points $(P=0.048)$. There was a correlation between impairment in BCVA and near vision (Spearman's rho $=0.57, P=0.001$ ). Visual outcome at the 37-month follow-up correlated with visual acuity at baseline $(P=0.001)$. There was a positive correlation between both the number of injections given and BCVA at baseline (Spearman's rho $=0.56, P=0.001$ ) and the number of injections given and BCVA at the 3-year follow-up (Spearman's rho $=0.67, P=0.001$ ).

In 16 of 51 patients $(31 \%)$, ETDRS letters and near vision increased over the 37-month observation period from $55 \pm 14$ to $69 \pm 11$ letters $(P=0.004)$, and $17 \pm 9$ to $7 \pm 6$ $(P=0.0001)$, respectively. These patients were the same age and had the same delay between onset of symptoms and the first visit as did patients whose vision decreased. BCVA was also the same at baseline in patients with a better outcome compared with those having a worse outcome, ie, $58 \pm 14$ letters versus $51 \pm 14$ letters $(P=0.10)$ and $15 \pm 10$ points versus $18 \pm 9$ points $(P=0.35)$, respectively. There was a trend toward an increased number of injections given in eyes with an improved visual outcome, ie, $9.5 \pm 5.1$ versus $6.9 \pm 4.5$ in eyes with a worse visual acuity outcome $(P=0.079)$.

\section{Treatment of the better or worse eye}

Twenty-six of 66 (39\%) patients had poor vision, with a near vision score over 24 points in the second nontreated eye at baseline. Near vision, visual acuity (ETDRS), and duration before treatment were the same compared with people with better vision in the second eye, but the number of injections differed, ie, 9.6 \pm 5.5 in patients with low vision in the second eye compared with $6.8 \pm 4.6(P=0.038)$ in the other patients. The same proportion of people with or without low vision in the second eye were monitored for 37 months (17/26 and 34/40, respectively, not statistically significant). In addition, fewer people with affection in the second eye achieved stable visual acuity in the treated eye (4/17 [25\%] versus $21 / 34$ [62\%], respectively, $P=0.016$ ). In patients treated in the better eye, visual acuity and near vision were the same at 3-year follow-up as at baseline, while patients treated in the worse-seeing eye showed a drop in visual acuity (ETDRS) from $51 \pm 14$ letters to $41 \pm 12$ letters $(P=0.014)$ after 3 years.

\section{Visual Function Questionnaire}

\section{At 3-month follow-up (all patients included, $\mathrm{n}=66$ )}

The quality of life test revealed an improvement in mental health (less worrying, better control) from $57 \pm 30$ points to $63 \pm 29$ points $(P=0.014)$ and in near vision-related items (reading newspaper, finding things on a crowded shelf, seeing well at close distance) from $48 \pm 24$ points to $56 \pm 28$ points $(P=0.002)$.

\section{At 37-month follow-up $(n=5 \mathrm{I})$}

The quality of life test at the 37-month follow-up did not indicate improvement in any questionnaire items. There was a decrease in scores for general health from $56 \pm 26$ points to $46 \pm 24$ points $(P=0.004)$, ocular pain from $83 \pm 22$ points to $74 \pm 29$ points $(P=0.028)$, color vision (matching clothes) from $81 \pm 30$ points to $65 \pm 30$ points $(P=0.001)$, and in distance activities (reading street signs, steps, theatre visit) from $57 \pm 27$ points to $46 \pm 31$ points $(P=0.007)$. There was also a decrease in vision-specific items, such as social functioning (seeing people's reactions, company) from $74 \pm 27$ points to $65 \pm 30$ points $(P=0.021)$ and role difficulties (limitations in performance) from $67 \pm 28$ points to $56 \pm 32$ points $(P=0.026)$.

\section{Patients with better visual acuity \\ at 37-month follow-up $(n=16)$}

In the 16 patients with an improvement in visual acuity at 37-month follow-up (change in ETDRS letters from 
$57 \pm 14$ letters to $69 \pm 11$ letters and in near vision from $15 \pm 10$ points to $7 \pm 6$ points), there was also an improvement in general vision items from $57 \pm 18$ to $70 \pm 25$ $(P=0.027)$.

\section{Patients with visual impairment} at 37-month follow-up $(n=35)$

Patients with visual impairment at 37-month follow-up (ETDRS letters $51 \pm 14$ letters to $34 \pm 20$ letters and near vision $18 \pm 9$ points to $25 \pm 8$ points) demonstrated a decrease in general health $(55 \pm 28$ points to $42 \pm 24$ points $P=0.003)$, worse distance activities (51 \pm 27 to $38 \pm 29$, $P=0.006$ ), and impaired color vision (matching clothes) (79 \pm 33 to $63 \pm 33, P=0.009$ ). In addition, there was a decline in response to social functioning questions $(70 \pm 29$ to $57 \pm 31, P=0.019$ ).

Patients with AMD in the other eye $(n=18)$ :

\section{better-seeing eye treated}

There was no change from baseline in visual outcome at 37-month follow-up in the treated eye (ETDRS $56 \pm 14$ letters to $53 \pm 18$ letters and near vision $13 \pm 8$ points to $16 \pm 10$ points) in patients with AMD in the second eye (Figure 1). Quality of life testing demonstrated a decrease in general health from $61 \pm 27$ points to $47 \pm 24$ points $(P=0.007)$, and increased dependency from $69 \pm 28$ points to $54 \pm 32$ points $(P=0.026)$. However, near activities improved from $34 \pm 16$ points to $40 \pm 24$ points $(P=0.001)$.

Patients with no AMD in the other eye $(n=34)$ : worse-seeing eye treated

There was a decrease in BCVA from $52 \pm 14$ letters to $41 \pm 25$ letters $(P=0.014)$ in the worse-seeing eye treated, but near vision was similar to baseline $(19 \pm 9$ points to $21 \pm 11$ points) at 3-year follow-up (Figure 1). Quality of life testing showed a decrease in color vision (matching clothes) from $87 \pm 29$ points to $69 \pm 29$ points $(P=0.002)$, and in distance activities from $64 \pm 27$ points to $51 \pm 31$ points $(P=0.018)$ at 37-month follow-up.

\section{Comparing patient groups with different outcomes}

No difference was observed in mean change from baseline scores over 37 months in pooled near activities, distance activities, or mental health-related items when comparing patients with the better-seeing eye treated versus worseseeing eye treated (Figure 2). However, when the group with improved BCVA was compared with the group with a worse

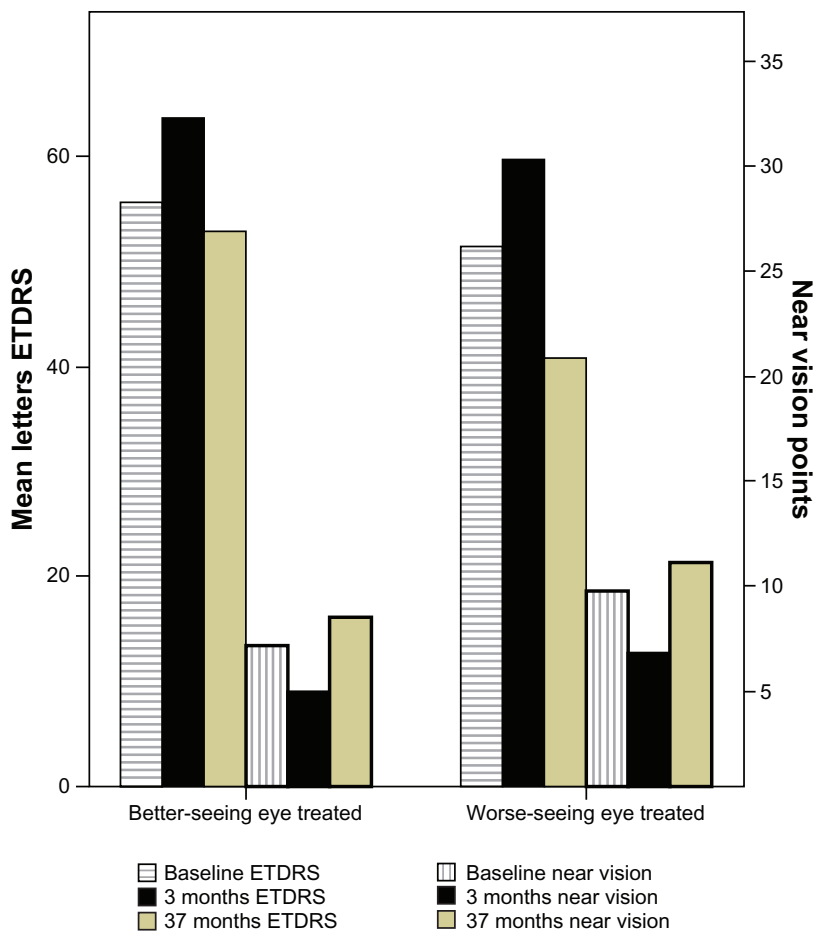

Figure I Mean best corrected visual acuity (ETDRS letters) and near vision (points) at baseline, and at 3-month and 37-month follow-up in the better-seeing eye treated and the worse-seeing eye treated.

Note: The three columns to the right in each group represent the ETDRS letters and the three to the left represent near vision.

Abbreviation: ETDRS, Early Treatment Diabetic Research Study.

BCVA outcome at follow-up, we demonstrated a difference in pooled near activities of $9 \pm 21$ points versus $-4.7 \pm 18$ points $(P=0.048$, see Figure 3$)$.

\section{Discussion}

This study demonstrated an improvement in BCVA by an average of eight letters on the ETDRS chart at 3-month follow-up. This is comparable with the findings of the MARINA study in occult $\mathrm{CNV}^{3}$ which showed an improvement after one year of 7.2 letters, and is slightly worse than those of the ANCHOR study in classic CNV ${ }^{4}$ which demonstrated an improvement of 11.3 letters after one year. At the 3-year follow-up in our study, BCVA decreased by an average of nine letters and we demonstrated worse BCVA than before treatment. This is in contrast with the 2-year follow-up results for MARINA, which showed an increase of 6.6 letters, and for the ANCHOR study, which showed an increase of 10.7 letters. However, the results are better than for the sham-treated eyes in MARINA, which lost an average of two lines by one year and three lines by 2 years, ${ }^{6}$ and in the PIER study, in which sham-treated eyes lost an average of three lines by one year. ${ }^{12}$ However, we demonstrated a result after 3 years but one that was not distinguished between 


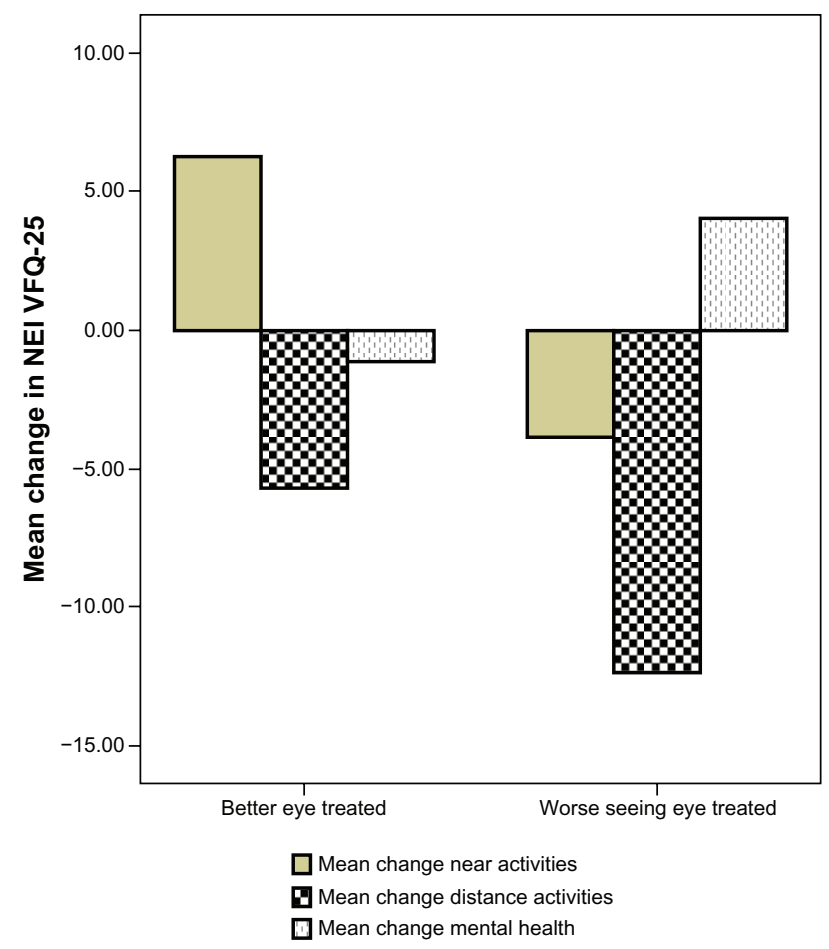

Figure 2 Pooled data for near activities (reading newspaper, seeing well at close distance, finding an item on crowded shelf), distance activities (street signs, steps, stairs in dim light), and mental health (worrying, "less control over what I am doing") items in patients with better-seeing eye treated compared with worse-seeing eye treated.

Abbreviation: NEI VFQ-25, National Eye Institute Visual Function Questionnaire.

different sorts of CNV. Furthermore, most importantly, the mean number of injections over the 3 years was only eight compared with monthly injections in the treatment arms in the other studies. Consequently, it seems most likely that the patients were under-treated in the present study, given that even the uncontrolled PRONTO study, ${ }^{13}$ which used three monthly injections initially followed by variable dosing, showed an increase of 11 letters after 2 years.

After the initiation phase, the strongest evidence is for continued monthly treatment, but this is often not feasible in clinical practice, so an individualized approach is the standard in many countries today. However, the risk is obvious, ie, there may be a delay in reinitiating treatment. It is reported that delayed initiation of treatment in patients with newly diagnosed AMD is associated with substantial BCVA loss. ${ }^{14}$ In the present study, the interval between diagnosis and treatment was the same, irrespective of the visual outcome.

Near vision, which is important for reading, has not been or is rarely studied. In a previous paper, Frennesson et $\mathrm{al}^{9}$ demonstrated an improvement in near reading from 9 to 6 points after three monthly injections with ranibizumab in patients with wet AMD. This is less than in our study, in which we showed an improvement from 17 to 11 points after

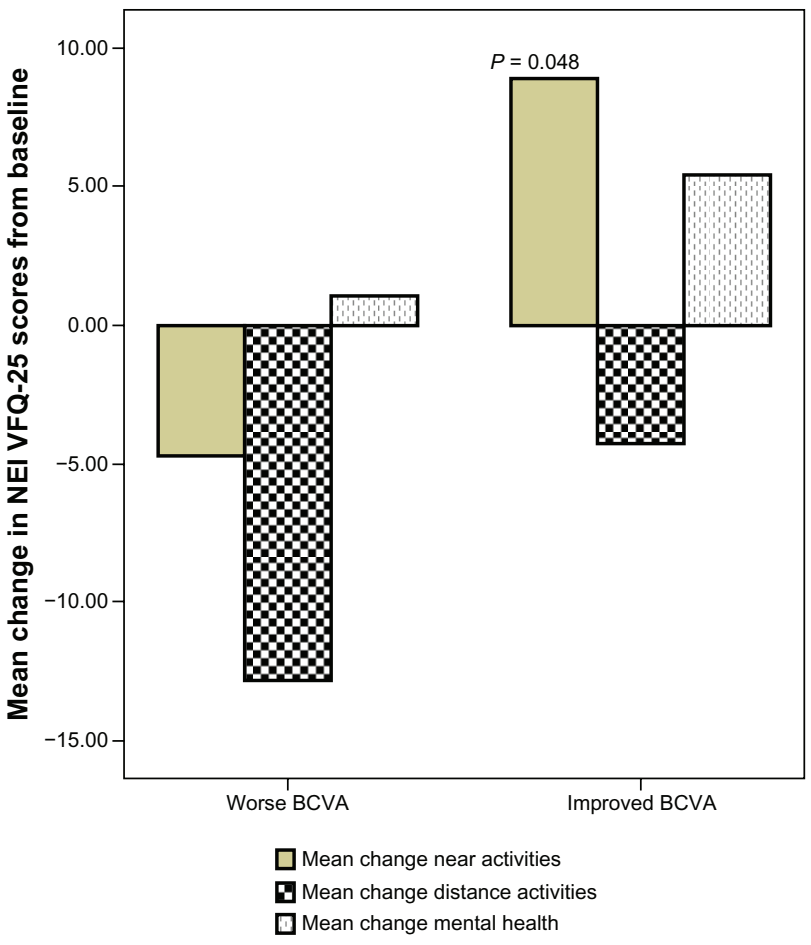

Figure 3 Pooled data for near activities (reading newspaper, seeing well at close distance, finding an item on crowded shelf), distance activities (street signs, steps, stairs in dim light), and mental health (worrying, "less control over what I am doing") items in patients with worse visual outcome compared to patients with improved visual outcome.

Abbreviations: BCVA, best corrected visual acuity; NEI VFQ-25, National Eye Institute Visual Function Questionnaire.

the first three injections. However, patients in the present study started at a lower visual acuity level, and worse baseline BCVA has been reported to result in better improvement. ${ }^{15}$ In contrast with the paper by Frennesson et al, we found a good correlation between changes in BCVA over time and near vision. This suggests that it may not be necessary to register the near vision parameter in order to assess the patient's vision status.

The NEI VFQ-25 has recently been demonstrated to respond well to changes in visual acuity. ${ }^{10}$ In the present study, mean changes in NEI VFQ-25 scores at 3 months for near activities are in agreement with the subanalyses from the MARINA and ANCHOR studies, ${ }^{16}$ and also with a recent paper by Frennesson et al who found a greater improvement for near vision-related activities than for distance-related items after 3 months of follow-up. ${ }^{9}$ Interestingly, we could also demonstrate an improvement in mental health-related items, like less worrying, at 3 months. The less favorable outcome of the NEI VFQ-25 after 37 months reflects the fact that the entire group had an impaired BCVA outcome, probably because of undertreatment. The positive correlation between number of injections given and visual outcome 
indicates that a more frequent treatment regime would have been favorable.

NEI VFQ-25 scores decreased on many of the questions but, interestingly, not in near activities items such as reading the newspaper and finding things on a crowded shelf. Mental health items like worrying and "less control over what I am doing" were also unchanged. The fact that the patients have received support and care while frequently visiting the outpatient clinic may have helped them to cope better with their visual disability. ${ }^{17}$

The NEI VFQ-25 analysis in the ANCHOR and MARINA studies demonstrated an association between improving visual acuity and decreased dependency and improved distance activities. ${ }^{10}$ We could not confirm that distance activities improved with a better visual outcome, but dependency increased with worse visual outcome.

Patients treated in the better-seeing eye had similar BCVA and near vision at follow-up as at baseline, which probably reflects the greater number of injections given, ie, 9.5 compared with 6.9. In spite of this, the NEI VFQ-25 test demonstrated worse general health and increased dependency, but there was an improvement in items correlated with near vision, such as the ability to read a newspaper.

Interestingly, no difference was observed when comparing the changes between baseline and at 37-month follow-up for pooled NEI VFQ-25 data on near and distance activities and mental health items between patients treated in the betterseeing or worse-seeing eye. Only near activities items proved to be significantly different between eyes with improved or decreased visual acuity outcome. The decrease in scores for general health in patients with two eyes affected contradicts a study that reported more depression among people with only one eye affected, on the basis that they would feel a greater uncertainty about the future. ${ }^{18}$

To our knowledge, this is the first quality of life study that has monitored patients with wet AMD treated using ranibizumab in routine care for 3 years. Although the number of patients in the study was not very high, the strength is that as many as $77 \%$ of the patients in the study completed the last NEI VFQ-25 interview at the 37-month follow-up.

In conclusion, at 3-year follow-up, we demonstrated a decrease in visual acuity in the majority of patients treated, probably due to undertreatment, which emphasizes the importance of treating AMD patients frequently and without delay. Decreased visual acuity was related to a decrease in self-reported visual function for distance activities, while mental health items like worrying were not influenced.

\section{Acknowledgments}

This study was supported by grants from the Medical Faculty, Lund University, the Skåne County Council Foundation for Research and Development, and Crown Princess Margareta's Committee for the Blind.

\section{Disclosure}

The authors report no conflicts of interest in this work.

\section{References}

1. Klaver CC, Wolfs RC, Vingerling JR, Hofman A, de Jong PT. Age specific prevalence and causes of blindness and visual impairment in an older population: the Rotterdam Study. Arch Ophthalmol. 1998;116(5):653-658.

2. Bressler NM. Age-related macular degeneration is the leading cause of blindness. JAMA. 2004;291(15):1900-1901.

3. Rosenfeld PJ, Brown DM, Heier JS, et al; for the MARINA Study Group. Ranibizumab for neovascular age-related macular degeneration. N Engl J Med. 2006;355(14):1419-1431.

4. Brown DM, Michels M, Kaiser PK, et al. Ranibizumab versus verteporfin photodynamic therapy for neovascular age-related macular degeneration: two-year results of the ANCHOR study. Ophthalmology. 2009;116(1):57-65.

5. Brown DM, Kaiser PK, Michels M, et al. Ranibizumab versus verteporfin for neovascular age-related macular degeneration. NEngl J Med. 2006;355(14):1432-1444.

6. Margolis MK, Coyne K, Kennedy-Martin T, Baker T, Schein O, Revicki DA. Vision-specific instruments for the assessment of healthrelated quality of life and visual functioning: a literature review. Pharmacoeconomics. 2002;(20):791-812.

7. Miskala PH, Hawkins BS, Mangione CM, et al. Responsiveness of the National Eye Institute Visual Function Questionnaire to changes in visual acuity: findings in patients with subfoveal choroidal neovascularization. SST report no 1. Arch Ophthalmol. 2003;121(4):531-539.

8. Miskala PH, Bressler NM, Meinert CL. Relative contributions of reduced vision and general health to NEI-VFQ scores in patients with neovascular age-related macular degeneration. Arch Ophthalmol. 2004;122(5):758-766.

9. Frennesson C, Nilsson U, Peebo B, Nilsson S. Significant improvement in near vision, reading speed, central visual field and related quality of life after ranibizumab treatment of wet age-related macular degeneration. Acta Ophthalmol. 2010;88(4):420-425.

10. Suñer IJ, Gregg T, Kokame, Yu E, Ward J, Dolan, Bressler NM. Responsiveness of NEI VFQ-25 to changes in visual acuity in neovascular AMD: validation studies from two phase 3 clinical trials. Invest Ophthalmol Vis Sci. 2009;50(8):3629-3635.

11. Mangione CM, Berry S, Spritzer K, et al. Identifying the content area for the National Eye Institute Vision Function Questionnaire (NEIVFQ): results from focus groups with visually impaired persons. Arch Ophthalmol. 1998;116(2):227-233.

12. Regillo CD, Brown DM, Abraham P, et al. Randomized, doublemasked, sham controlled trial of ranibizumab for neovascular agerelated macular degeneration: PIER Study year 1. Am J Ophthalmol. 2008;145(2):239-248.

13. Fung AE, Lalwani GA, Rosenfeld PJ, et al. An optical coherence tomography guided, variable dosing regimen with intravitreal ranibizumab (Lucentis) for neovascular age-related macular degeneration. Am J Ophthalmol. 2007;143(4):566-583.

14. Arias L, Armada F, Donate J, et al. Delay in treating age-related macular degeneration in Spain is associated with progressive vision loss. Eye. 2009;23(2):326-333.

15. Boyer DS, Antoszyk AN, Awh CC, Bhisitkul RB, Shapiro H, Acharya NR. MARINA Subgroup analysis of the MARINA study of ranibizumab in neovascular age-related macular degeneration. Ophthalmology. 2007;114(2):246-252. 
16. Bressler NM, Chang TS, Suñer IJ, et al. Vision-related function after ranibizumab treatment by better- or worse-seeing eye. Ophthalmology. 2010;117(4):747-756

17. Scott IU, Smiddy WE, Schiffman J, Feuer WJ, Pappas CJ. Quality of life of low-vision patients and the impact of low-vision services. Am J Ophthalmol. 1999;128(1):54-62.
18. Slakter JS, Stur M. Quality of life in patients with age-related macular degeneration: impact of the condition and benefits of treatment. Surv Ophthalmol. 2005;50(3):263-272.

\section{Publish your work in this journal}

Clinical Ophthalmology is an international, peer-reviewed journal covering all subspecialties within ophthalmology. Key topics include: Optometry; Visual science; Pharmacology and drug therapy in eye diseases; Basic Sciences; Primary and Secondary eye care; Patien Safety and Quality of Care Improvements. This journal is indexed on

Submit your manuscript here: http://www.dovepress.com/clinical-ophthalmology-journal

\section{Dovepress}

PubMed Central and CAS, and is the official journal of The Society of Clinical Ophthalmology (SCO). The manuscript management system is completely online and includes a very quick and fair peer-review system, which is all easy to use. Visit http://www.dovepress.com/ testimonials.php to read real quotes from published authors. 